\title{
Damage and Seismic Intensity of the 1996 Lijiang Earthquake, China: A GIS Analysis
}

\author{
HE Honglin*, OGUCHI Takashi*, ZHOU Ruiqi**, \\ ZHANG Jianguo** and QIAO Sen** \\ *Center for Spatial Information Science, University of Tokyo, Bunkyo, Tokyo 113-0086, Japan \\ **Yunnan Seismological Bureau, Kunming, Yunnan 650041, China
}

\begin{abstract}
The damage caused by the 1996 Lijiang earthquake in China was analyzed using Geographic Information Systems (GIS). Data for the Lijiang district were collected from the local government offices and were converted into GIS data layers. The damage ratio of houses, seismic intensity and the occurrence of casualties were mapped. The results show that the distributions of seismic intensity and the damage ratio of houses reflect the occurrence of thick alluvium and the structure of fault systems.
\end{abstract}

Key words: the 1996 Lijiang earthquake, damage index, seismic intensity, GIS

\section{Introduction}

The four recent large earthquakes in Asia, the 1995 Kobe in Japan, the 1996 Lijiang in China, the $1999 \mathrm{Jjij}$ in Taiwan and the 2001 Bhuj in India led to catastrophic disasters. Evaluation of such earthquake disasters serves for damage mitigation and future city planning. Studies concerning the 1995 Kobe (Hanshin-Awaji) earthquake in Japan (e.g. Usui and Konagaya 1995; Iwai et al. 1996; Hatayama et al. 1999) have shown that GIS (Geographic Information Systems) provide useful tools for evaluating earthquake disasters.

In recent years, many Chinese researchers have been interested in computer analysis of earthquake disasters. For example, China Seismological Bureau (1998) developed software "Earthquake Disaster Loss Estimation System (EDLES)" with a graphic user interface for the Windows operation system. GIS applications to earthquakes in China, however, have been limited to the mapping of seismic zones (e.g., Zhou 2001). It is necessary to analyze earthquake damage in China using GIS, although governmental restrictions generally prevent access to data for disasters in China.

On the 3rd of February, 1996, a severe earthquake with a magnitude of 7.0 in the Richter scale shook Lijiang and surrounding areas of
Yunnan Province in China (Figure 1). It affected more than one million people in nine counties of four administration districts (Lijiang, Dali, Diqing, and Nujiang), resulting in the death of 309 people and the injury of 17,057 people. More than one million houses were damaged and many public infrastructures and facilities were broken. The economic loss due to the earthquake amounts to 2.583 billion RMB or ca. 320 million US dollars (Liu 1998a). We collected information regarding the damage of the Lijiang earthquake, and converted them into GIS data for analysis.

\section{Data}

\section{Building damage ratios and earthquake dam- age index}

About 10 hours after the Lijiang earthquake, the field investigation team of the Yunnan Seismological Bureau arrived in Lijiang to collect information about the damage. Although some general reports were published based on the collected data (Huangfu 1997; Han and Zhou 1997), most of these data have been classified by the local government. We were, however, allowed to use the data of building damage ratios for 111 villages and death toll in the Lijiang district.

Han and Zhou (1997) proposed the classifica- 


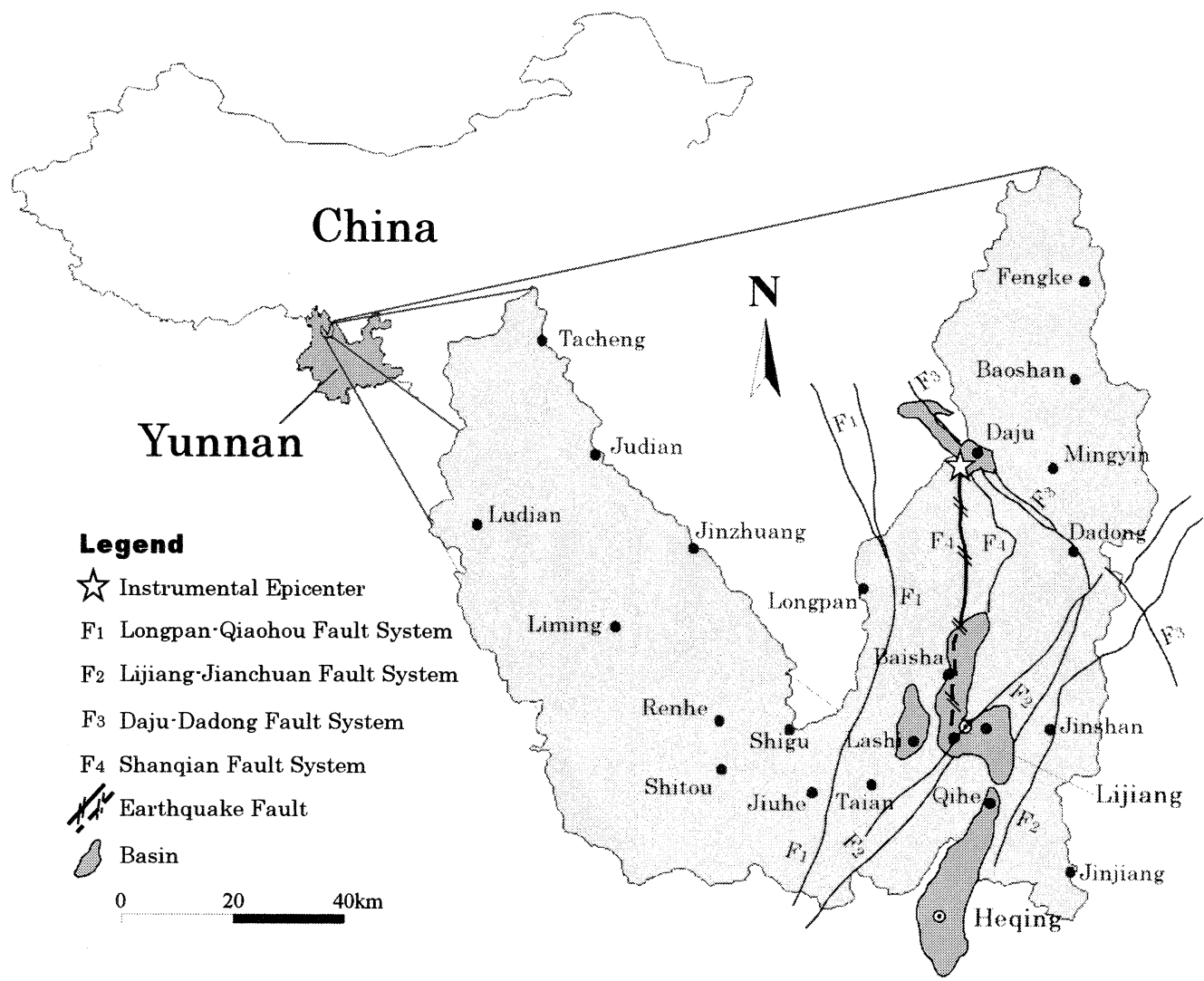

Figure 1. Map of Lijiang County.

Each fault system consists of a few faults.

Table 1. Classification of houses in China

\begin{tabular}{|c|c|}
\hline Type & Description \\
\hline I & $\begin{array}{l}\text { Simple and crude sheds, made of sun-dried mud brick and/or rubble, covered with straw and } \\
\text { mud }\end{array}$ \\
\hline II & $\begin{array}{l}\text { 1) Low-cost houses, made of rammed earth, sun-dried mud brick and/or rubble; 2) old wood- } \\
\text { framed houses }\end{array}$ \\
\hline III & $\begin{array}{l}\text { 1) Firm wood-framed houses such as temples; 2) modern houses made of brick and rubble; } 3 \text { ) } \\
\text { houses made of brick and concrete; 4) houses framed with concrete }\end{array}$ \\
\hline
\end{tabular}

Source: Xie 1957.

tion of buildings and damage grades applicable to the Lijiang earthquake. In China, houses are divided into three types: I, II, and III (Xie 1957; Table 1). Han and Zhou (1997) note that most houses affected by the Lijiang earthquake belong to the types II and III, and that they can be further divided into eight sub-types shown in Table 2.

Xie (1957) classified building damage due to earthquakes into four grades. Han and Zhou
(1997) modified this classification and applied five damage grades to the Lijiang earthquake (Table 3).

Investigation Team of Earthquake Influence Field of Tonghai Earthquake (1977) introduced the damage index $(D I)$ to quantify the degree of earthquake damage. The estimation of $D I$ is threefold: 1) selection of a representative type of house; 2) estimation of the ratio of damage grades for the house type; and 3) calculation of 
Table 2. Classification of houses in the Lijiang district

\begin{tabular}{|c|c|c|}
\hline Type & & Description \\
\hline II-1 & \multicolumn{2}{|c|}{ Houses made of rammed earth including some crushed stones, covered with tiles } \\
\hline $\mathrm{II}-2$ & \multicolumn{2}{|c|}{$\begin{array}{l}\text { Houses made of sun-dried mud brick with wood frames; walls are made of sun-dried brick or } \\
\text { rammed earth; struts consist of irregular wood frames; covered with tiles }\end{array}$} \\
\hline II-3 & \multicolumn{2}{|c|}{$\begin{array}{l}\text { Houses made of sun-dried mud brick with brick pillars; walls are made of sun-dried brick; struts } \\
\text { consist of brick pillars; frames are made of wood, covered with tiles }\end{array}$} \\
\hline II-4 & \multicolumn{2}{|c|}{$\begin{array}{l}\text { Single-story houses made of brick; struts are made of lower-level concrete; frames are made of } \\
\text { wood; covered with tiles }\end{array}$} \\
\hline III-1 & \multicolumn{2}{|c|}{$\begin{array}{l}\text { Naxi tribe's houses made of wood and earth; wood frames bear the load; walls are made of earth } \\
\text { and covered with tiles; usually two stories and about } 7 \mathrm{~m} \text { in height; known as the Naxi nationa } \\
\text { folklore houses }\end{array}$} \\
\hline III-2 & \multicolumn{2}{|c|}{$\begin{array}{l}\text { Naxi tribe's houses made of wood and brick; frames are similar to those of III-1; walls are made of } \\
\text { brick }\end{array}$} \\
\hline III-3 & \multicolumn{2}{|c|}{$\begin{array}{l}\text { Houses made of brick and concrete; two or three stories; built after the } 1980 \mathrm{~s} \text {; struts consist of } \\
\text { steel and concrete pillars to resist earthquakes with Intensity VIII }\end{array}$} \\
\hline III-4 & \multicolumn{2}{|c|}{$\begin{array}{l}\text { Houses framed by steel and concrete, including buildings taller than four stories; usually } \\
\text { designed to resist earthquakes with Intensity VIII or higher. }\end{array}$} \\
\hline \multicolumn{3}{|c|}{ Source: Han and Zhou 1997.} \\
\hline & Grade & Description \\
\hline \multicolumn{2}{|c|}{ 1: collapsed } & Collapsed or seriously damaged; removal and reconstruction are needed \\
\hline \multicolumn{2}{|c|}{ 2: terribly damaged } & $\begin{array}{l}\text { Serious damage to principal parts or partly collapsed; intensive repair and } \\
\text { partial removal are needed }\end{array}$ \\
\hline \multicolumn{2}{|c|}{ 3: moderately damaged } & $\begin{array}{l}\text { Obvious damage to non-principal parts and/or some damage to principal } \\
\text { parts; can be used after repair or reinforcement }\end{array}$ \\
\hline \multicolumn{2}{|c|}{ 4: slightly damaged } & $\begin{array}{l}\text { Damage to non-principal parts and/or slight damage to principal parts; can } \\
\text { be used without repair }\end{array}$ \\
\hline \multicolumn{2}{|c|}{ 5: little damage } & No damage or very slight damage to non-principal parts \\
\hline
\end{tabular}

Source: Han and Zhou 1997.

Table 4. Standard earthquake disaster parameter applied to the Lijiang earthquake

\begin{tabular}{lccccc}
\hline Damage grade & 5 & 4 & 3 & 2 & 1 \\
Standard damage parameter & 0 & 0.2 & 0.4 & 0.7 & 1.0 \\
\hline
\end{tabular}

$D I$ using the following formula:

$$
D I=\sum_{\mathrm{j}} \mathrm{p}_{\mathrm{j}} \cdot A R_{\mathrm{j}}
$$

where $\mathrm{j}$ is the damage grade $(1,2, \cdots \mathrm{n}), \mathrm{p}_{\mathrm{j}}$ is the standard damage parameter for the $\mathrm{j}$-th damage grade and $A R_{\mathrm{j}}$ is the areal ratio of houses belonging to the $\mathrm{j}$-th damage grade. In the area affected by the Lijiang earthquake, Naxi tribe's houses of the III-1 type occurred widely, and thus they are suitable for the calculation of $D I$. Investigation Team of Earthquake Influence Field of Tonghai Earthquake (1977) determined the values of $\mathrm{p}_{\mathrm{j}}$ for such houses made of wood and earth. Using these values, we derived $\mathrm{p}_{j}$ corresponding to the five damage grades of Han and Zhou (1997) (Table 4). Table 5 shows the areal ratios of houses with different damage grades for the 111 villages, as well as the $D I$ calculated using Eq. (1).

\section{Seismic intensity}

Xie (1957) proposed 12 grades of seismic intensity applicable to China, and China Seismological Bureau (1977) estimated DI correspond- 
Table 5. Areal ratio of III-1-type houses with different damage grades, $\left(A R_{1}\right.$ to $\left.A R_{5}\right)$, damage index $(D I)$ and estimated seismic intensity for 111 villages

\begin{tabular}{|c|c|c|c|c|c|c|c|c|}
\hline No. & Village & $A R_{1}$ & $A R_{2}$ & $A R_{3}$ & $A R_{4}$ & $A R_{5}$ & $D I$ & Est. Intensity \\
\hline 1 & Mingyin & 0.05 & 0.42 & 0.38 & 0.15 & 0 & 0.52 & IX \\
\hline 2 & Daju (Yingpan) & 0.04 & 0.83 & 0.12 & 0 & 0 & 0.68 & IX \\
\hline 3 & Toutai & 0 & 0.06 & 0.88 & 0.03 & 0.03 & 0.4 & VIII \\
\hline 4 & Guoluo & 0.06 & 0.56 & 0.39 & 0 & 0 & 0.61 & IX \\
\hline 5 & Yuhu & 0.06 & 0.65 & 0.29 & 0 & 0 & 0.63 & IX \\
\hline 6 & Yulong & 0.09 & 0.64 & 0.27 & 0 & 0 & 0.65 & IX \\
\hline 7 & Wenhuazhongcun & 0.19 & 0.43 & 0.26 & 0.12 & 0 & 0.62 & IX \\
\hline 8 & Longshan & 0.13 & 0.42 & 0.33 & 0.11 & 0 & 0.58 & IX \\
\hline 9 & Xiacun & 0.15 & 0.5 & 0.33 & 0.02 & 0 & 0.57 & IX \\
\hline 10 & Wenhua & 0.31 & 0.38 & 0.31 & 0 & 0 & 0.65 & IX \\
\hline 11 & Shipingxiacun & 0.25 & 0.32 & 0.42 & 0 & 0 & 0.64 & IX \\
\hline 12 & Jinshan & 0.12 & 0.34 & 0.51 & 0.03 & 0 & 0.57 & IX \\
\hline 13 & Dadong & 0.3 & 0.46 & 0.17 & 0.07 & 0 & 0.7 & IX \\
\hline 14 & Liangmei & 0.36 & 0.26 & 0.32 & 0.06 & 0 & 0.68 & IX \\
\hline 15 & Wutai & 0.11 & 0.81 & 0.08 & 0 & 0 & 0.69 & IX \\
\hline 16 & Shanglidu & 0 & 0.67 & 0.16 & 0.13 & 0.15 & 0.59 & IX \\
\hline 17 & Kazi & 0.04 & 0.11 & 0.18 & 0.41 & 0.26 & 0.27 & VII \\
\hline 18 & Mingyin (Xicaiban) & 0.33 & 0.46 & 0.01 & 0.03 & 0.48 & 0.46 & VIII \\
\hline 19 & Boliluo & 0.03 & 0.07 & 0.47 & 0.37 & 0.06 & 0.34 & VIII \\
\hline 20 & Buguzi & 0 & 0.45 & 0.36 & 0.05 & 0.09 & 0.47 & VIII \\
\hline 21 & Xuehuacun & 0 & 0.42 & 0.32 & 0.26 & 0 & 0.47 & VIII \\
\hline 22 & Laozhichang & 0.07 & 0.81 & 0.12 & 0 & 0 & 0.67 & IX \\
\hline 23 & Qingsong & 0.12 & 0.41 & 0.47 & 0 & 0 & 0.5 & VIII \\
\hline 24 & Longshantou & 0 & 0.9 & 0.05 & 0.05 & 0 & 0.65 & IX \\
\hline 25 & Yiwanshui & 0.13 & 0.8 & 0.07 & 0 & 0 & 0.71 & $\mathrm{X}$ \\
\hline 26 & Xinhuoshan & 0.31 & 0.42 & 0.16 & 0.11 & 0 & 0.69 & IX \\
\hline 27 & Jiuzihai & 0.41 & 0.53 & 0.06 & 0 & 0 & 0.78 & $\mathrm{X}$ \\
\hline 28 & Xiangyang & 0 & 0.7 & 0.3 & 0 & 0 & 0.62 & IX \\
\hline 29 & Gantangzi & 0.26 & 0.59 & 0.15 & 0 & 0 & 0.48 & VIII \\
\hline 30 & Lariguang & 0.32 & 0.57 & 0.07 & 0 & 0 & 0.75 & $\mathrm{X}$ \\
\hline 31 & Wenming & 0 & 0.61 & 0.38 & 0 & 0 & 0.58 & IX \\
\hline 32 & Xiachangshui & 0 & 0.01 & 0.79 & 0.2 & 0 & 0.36 & VIII \\
\hline 33 & Wenbi & 0.04 & 0.25 & 0.61 & 0.1 & 0 & 0.49 & VIII \\
\hline 34 & Xiashuhe & 0 & 0.45 & 0.22 & 0 & 0 & 0.47 & VIII \\
\hline 35 & Zhonghe & 0.05 & 0.81 & 0.12 & 0 & 0 & 0.66 & IX \\
\hline 36 & Xilinwa & 0.06 & 0.87 & 0.03 & 0.05 & 0 & 0.69 & IX \\
\hline 37 & Dalai & 0.06 & 0.4 & 0.46 & 0.08 & 0 & 0.54 & IX \\
\hline 38 & Qiliang & 0.22 & 0.45 & 0.3 & 0.02 & 0 & 0.65 & IX \\
\hline 39 & Zegu & 0.12 & 0.73 & 0.14 & 0.01 & 0 & 0.69 & IX \\
\hline 40 & Shangcunren & 0.83 & 0.16 & 0.01 & 0 & 0 & 0.94 & $\mathrm{X}$ \\
\hline 41 & Wenzhi & 0.93 & 0.07 & 0 & 0 & 0 & 0.93 & $\mathrm{X}$ \\
\hline 42 & Tuanshang & 0 & 0.15 & 0.85 & 0 & 0 & 0.44 & VIII \\
\hline 43 & Luocheng & 0 & 0.23 & 0.61 & 0.12 & 0 & 0.47 & VIII \\
\hline 44 & Qingxi & 0.06 & 0.29 & 0.35 & 0.29 & 0 & 0.45 & VIII \\
\hline 45 & Meiluo & 0 & 0.2 & 0.76 & 0.44 & 0 & 0.52 & IX \\
\hline 46 & Zhonghai & 0.55 & 0.45 & 0 & 0 & 0 & 0.87 & $\mathrm{X}$ \\
\hline 47 & Qihe & 0 & 0.43 & 0.32 & 0.25 & 0 & 0.48 & VIII \\
\hline 48 & Shudi & 0 & 0.42 & 0.33 & 0.25 & 0 & 0.47 & VIII \\
\hline 49 & Junliang & 0.06 & 0.27 & 0.62 & 0.04 & 0 & 0.38 & VIII \\
\hline 50 & Yachakou & 0.03 & 0.03 & 0.58 & 0.22 & 0.14 & 0.33 & VIII \\
\hline 51 & Xinmin & 0.03 & 0.06 & 0.89 & 0.02 & 0 & 0.43 & VIII \\
\hline 52 & Geben & 0.08 & 0.19 & 0.27 & 0.32 & 0.14 & 0.39 & VIII \\
\hline 53 & Shengsepo & 0 & 0.31 & 0.38 & 0.15 & 0.16 & 0.4 & VIII \\
\hline 54 & Yongan & 0 & 0.24 & 0.45 & 0.3 & 0 & 0.41 & VIII \\
\hline 55 & Xinminzhongcun & 0 & 0.16 & 0.24 & 0.49 & 0.11 & 0.31 & VIII \\
\hline 56 & Sangu & 0 & 0.23 & 0.32 & 0.29 & 0.16 & 0.35 & VIII \\
\hline 57 & Zengming & 0 & 0.2 & 0.35 & 0.3 & 0.15 & 0.34 & VIII \\
\hline 58 & Jiyu & 0.03 & 0.05 & 0.44 & 0.43 & 0.05 & 0.33 & VIII \\
\hline
\end{tabular}


Table 5. Continued

\begin{tabular}{|c|c|c|c|c|c|c|c|c|}
\hline No. & Village & $A R_{1}$ & $A R_{2}$ & $A R_{3}$ & $A R_{4}$ & $A R_{5}$ & $D I$ & Est. Intensity \\
\hline 59 & Lashi & 0.08 & 0.1 & 0.17 & 0.36 & 0.29 & 0.3 & VII \\
\hline 60 & Haidong & 0.08 & 0.28 & 0.53 & 0.05 & 0.06 & 0.59 & IX \\
\hline 61 & Enzuo & 0 & 0.01 & 0.44 & 0.44 & 0.11 & 0.37 & VIII \\
\hline 62 & Lijiang & 0.01 & 0.01 & 0.31 & 0.69 & 0.01 & 0.26 & VII \\
\hline 63 & Changsong & 0 & 0.03 & 0.04 & 0.5 & 0.43 & 0.26 & VII \\
\hline 64 & Jiangbian & 0.2 & 0.14 & 0.48 & 0.15 & 0.03 & 0.59 & IX \\
\hline 65 & Haba & 0.02 & 0.06 & 0.43 & 0.45 & 0.28 & 0.33 & VIII \\
\hline 66 & Baidi & 0.01 & 0.3 & 0.2 & 0.39 & 0.09 & 0.39 & VIII \\
\hline 67 & Meizi & 0.45 & 0.36 & 0.13 & 0.02 & 0.04 & 0.7 & IX \\
\hline 68 & Xintun & 0 & 0.21 & 0.38 & 0.36 & 0.05 & 0.37 & VIII \\
\hline 69 & Jinsuo & 0 & 0.17 & 0.18 & 0.65 & 0 & 0.32 & VIII \\
\hline 70 & Zhongjicun & 0 & 0.03 & 0.07 & 0.89 & 0 & 0.23 & VII \\
\hline 71 & Tianxin & 0.01 & 0 & 0.13 & 0.86 & 0 & 0.23 & VII \\
\hline 72 & Qiaotou & 0 & 0 & 0.06 & 0.9 & 0.04 & 0.2 & VII \\
\hline 73 & Gaoshicun & 0.07 & 0 & 0.08 & 0.5 & 0.35 & 0.2 & VII \\
\hline 74 & Guifeng (Sanyuan) & 0.05 & 0.39 & 0.56 & 0 & 0 & 0.55 & IX \\
\hline 75 & Shounan & 0.01 & 0.15 & 0.65 & 0.19 & 0 & 0.41 & VIII \\
\hline 76 & Baojicun & 0.01 & 0.04 & 0.7 & 0.25 & 0 & 0.37 & VIII \\
\hline 77 & Guangming & 0 & 0.08 & 0.24 & 0.27 & 0.41 & 0.21 & VII \\
\hline 78 & Shimenkan & 0 & 0.09 & 0.19 & 0.2 & 0.52 & 0.18 & VII \\
\hline 79 & Xichuan & 0 & 0.13 & 0.25 & 0.21 & 0.41 & 0.23 & VII \\
\hline 80 & Changping & 0 & 0.1 & 0.3 & 0.24 & 0.36 & 0.24 & VII \\
\hline 81 & Guantian & 0 & 0.12 & 0.25 & 0.29 & 0.34 & 0.24 & VII \\
\hline 82 & Jiuhe & 0 & 0.06 & 0.27 & 0.3 & 0.37 & 0.21 & VII \\
\hline 83 & Xinren & 0 & 0.08 & 0.22 & 0.39 & 0.31 & 0.22 & VII \\
\hline 84 & Sanba & 0 & 0.09 & 0.25 & 0.35 & 0.31 & 0.23 & VII \\
\hline 85 & Yitou & 0 & 0.12 & 0.24 & 0.28 & 0.37 & 0.24 & VII \\
\hline 86 & Hongmai & 0 & 0 & 0.4 & 0.47 & 0.13 & 0.25 & VII \\
\hline 87 & Daan & 0 & 0.09 & 0.36 & 0.18 & 0.36 & 0.24 & VII \\
\hline 88 & Songping & 0 & 0.13 & 0.26 & 0.23 & 0.38 & 0.24 & VII \\
\hline 89 & Puzi & 0 & 0 & 0.06 & 0.47 & 0.47 & 0.12 & VII \\
\hline 90 & Longpan (Xinlian) & 0 & 0.1 & 0.4 & 0.32 & 0.18 & 0.29 & VII \\
\hline 91 & Tuguancun & 0 & 0 & 0.22 & 0.33 & 0.45 & 0.16 & VII \\
\hline 92 & Runan & 0.04 & 0.08 & 0.36 & 0.4 & 0.12 & 0.33 & VIII \\
\hline 93 & Jizi & 0 & 0.11 & 0.28 & 0.39 & 0.22 & 0.27 & VII \\
\hline 94 & Dachang & 0 & 0 & 0.17 & 0.23 & 0.6 & 0.11 & VII \\
\hline 95 & Qingkou & 0 & 0 & 0.08 & 0.12 & 0.8 & 0.05 & VI \\
\hline 96 & Shigu & 0 & 0.02 & 0.03 & 0.05 & 0.9 & 0.03 & VI \\
\hline 97 & Dongling & 0 & 0 & 0.2 & 0.05 & 0.75 & 0.09 & VI \\
\hline 98 & Diannan & 0 & 0.01 & 0.07 & 0.37 & 0.55 & 0.1 & VI \\
\hline 99 & Xiaozhongdian & 0 & 0 & 0 & 0.68 & 0.32 & 0.13 & VII \\
\hline 100 & Songgui & 0 & 0 & 0.11 & 0.21 & 0.68 & 0.08 & VI \\
\hline 101 & Meiyuan & 0 & 0 & 0.16 & 0.27 & 0.57 & 0.11 & VII \\
\hline 102 & Xiyi & 0 & 0 & 0.09 & 0.3 & 0.61 & 0.1 & VI \\
\hline 103 & Duomei & 0 & 0 & 0.12 & 0.18 & 0.7 & 0.08 & VI \\
\hline 104 & Lanping & 0 & 0 & 0.1 & 0.2 & 0.7 & 0.08 & VI \\
\hline 105 & Hongqiao & 0 & 0 & 0.04 & 0.33 & 0.63 & 0.09 & VI \\
\hline 106 & Jiulong & 0 & 0 & 0 & 0.75 & 0.25 & 0.15 & VII \\
\hline 107 & Annan & 0 & 0 & 0 & 0.38 & 0.62 & 0.08 & VI \\
\hline 108 & Paomaping & 0 & 0 & 0 & 0.2 & 0.8 & 0.04 & VI \\
\hline 109 & Yongning & 0 & 0 & 0.15 & 0.82 & 0.03 & 0.22 & VII \\
\hline 110 & Jinguan & 0 & 0 & 0.1 & 0.29 & 0.61 & 0.09 & VI \\
\hline 111 & Junhe & 0 & 0 & 0.01 & 0.51 & 0.48 & 0.1 & VI \\
\hline
\end{tabular}

ing to these grades (Table 6). The seismic intensity estimated from $D I$ for the 111 villages in the Lijiang district is shown in Table 5. Although such intensity estimation requires de- tailed data of building damage ratios, seismic intensity has often been approximated based on rapid field observations of the damage. For example, Han and Zhou (1997) drew contours of 


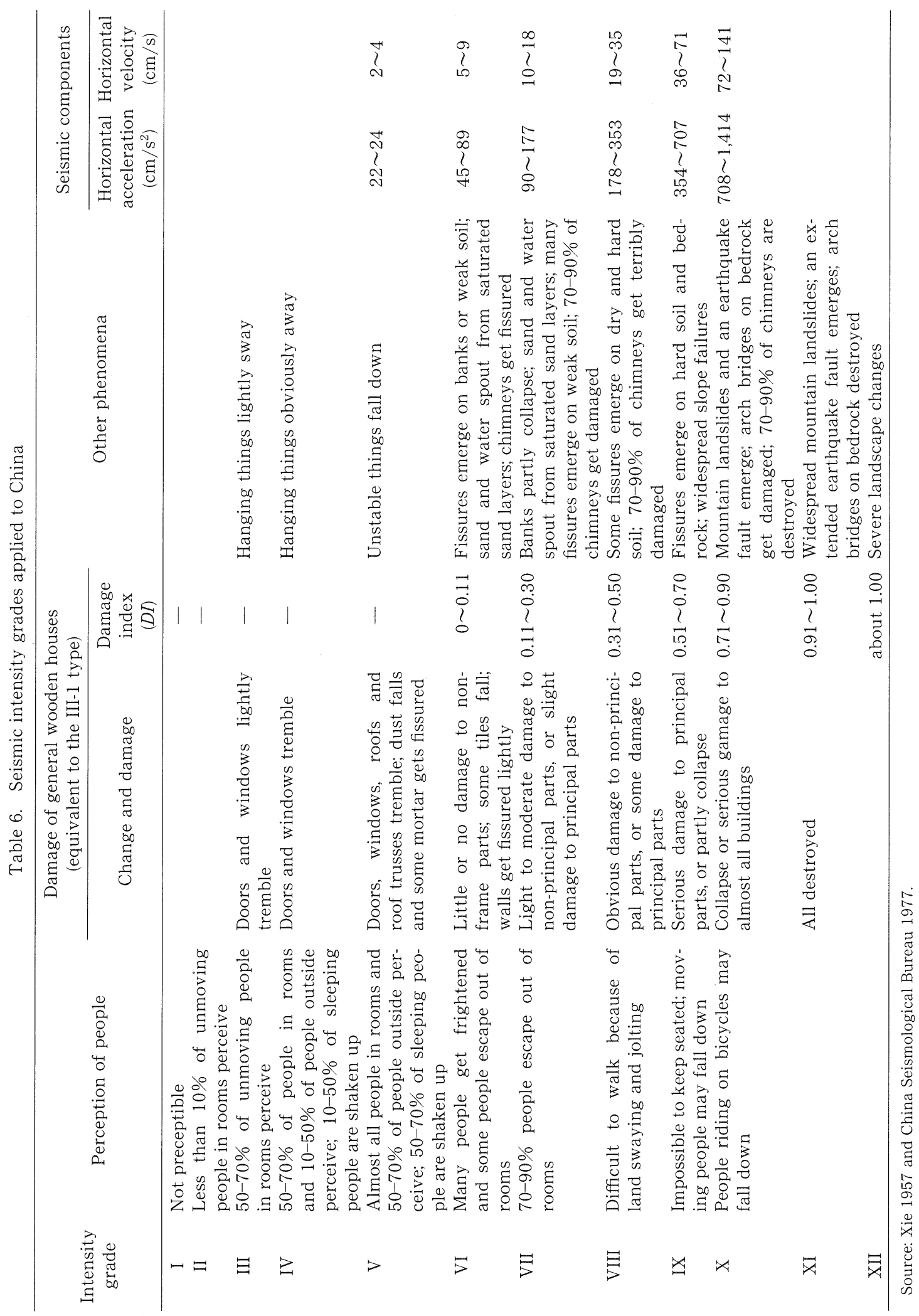


the intensity of the Lijiang earthquake based on rapid observations in 36 towns (Figure 2).

\section{Death toll}

Among the 309 people killed by the Lijiang earthquake, 294 died in Lijiang County. We obtained the death toll data for Lijiang County from the seismological office of the county. Among 294 victims, 241 were directly crushed to death below the collapsed buildings, 25 died because of injury, 2 died because of fire, 3 died because of shock, 6 died because of suffocation and 16 died for other reasons. Major victims were children and aged people (Table 7).

\section{Mapping and Analysis of Earthquake Damage Using GIS}

The tabulated data concerning house damage and death toll were converted into GIS data with geographic coordinates. Some paper maps were also digitized to provide the electronic files of basic map components such as adminis-

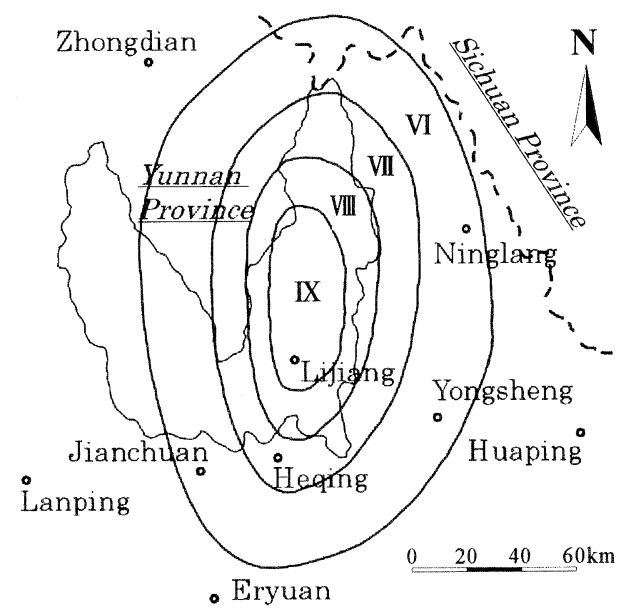

Figure 2. Contours of seismic intensity based on rapid field observations. Source: Han and Zhou 1997.

Table 7. Death toll according to age

\begin{tabular}{lccccccccc}
\hline Age & $<10$ & $10-19$ & $20-29$ & $30-39$ & $40-49$ & $50-59$ & $60-69$ & $>70$ & unknown \\
Number & 58 & 23 & 18 & 19 & 16 & 28 & 42 & 61 & 29 \\
\hline
\end{tabular}

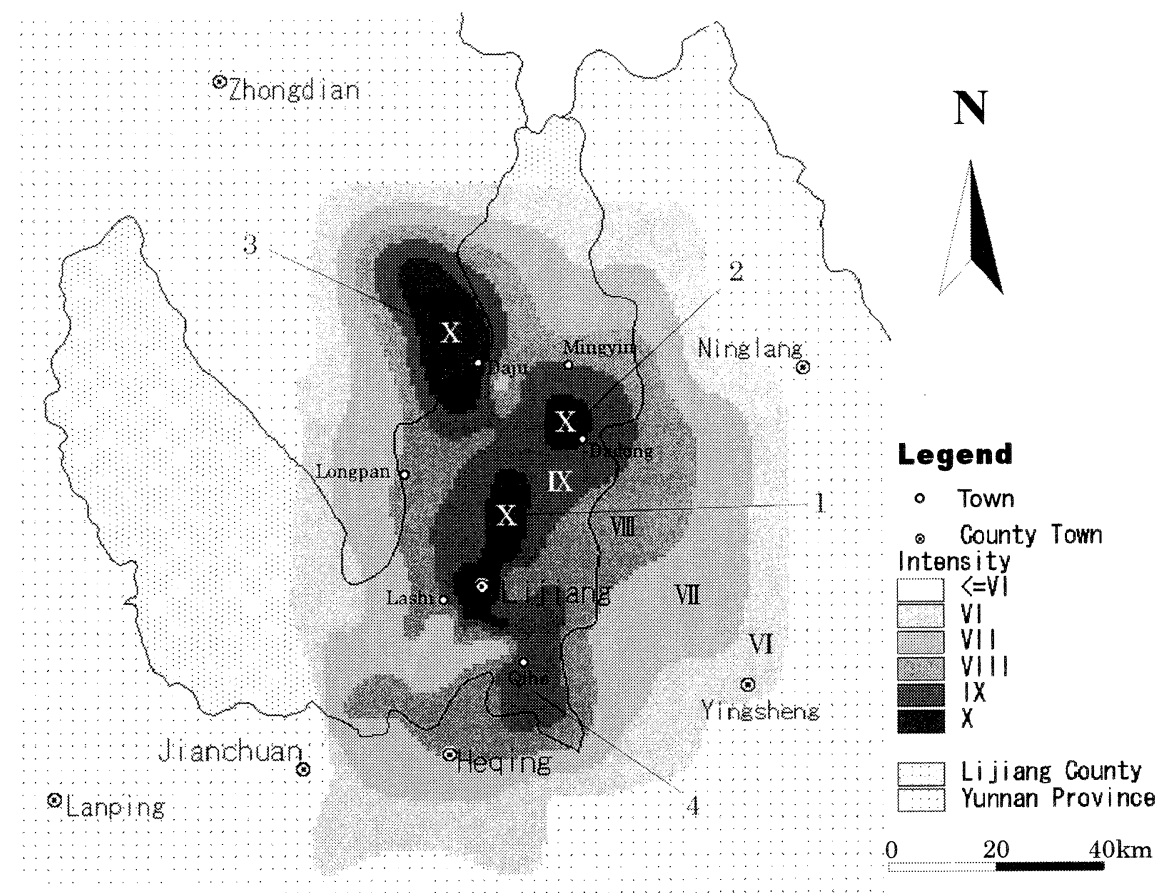

Figure 3. Distribution of seismic intensity based on the damage index. 

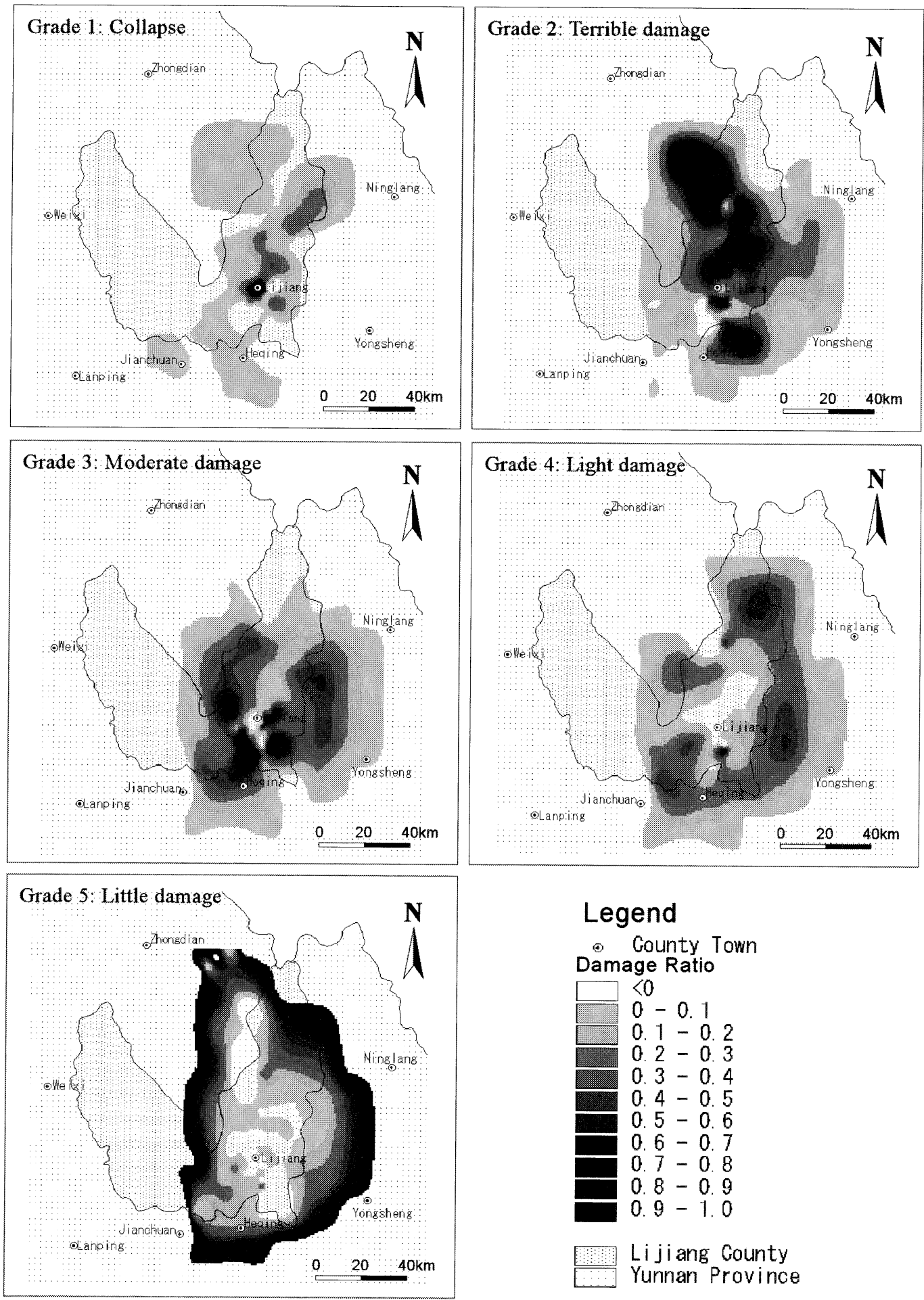

\section{Legend}
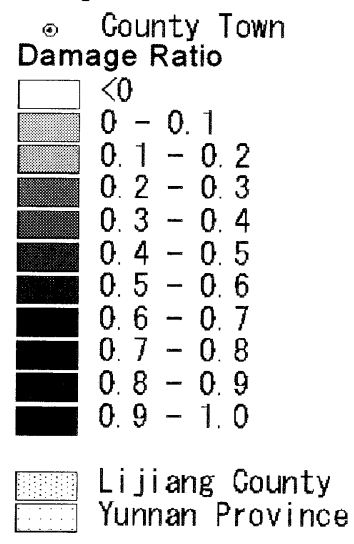

Figure 4. Distribution of areal ratio of buildings belonging to each damage grade. 


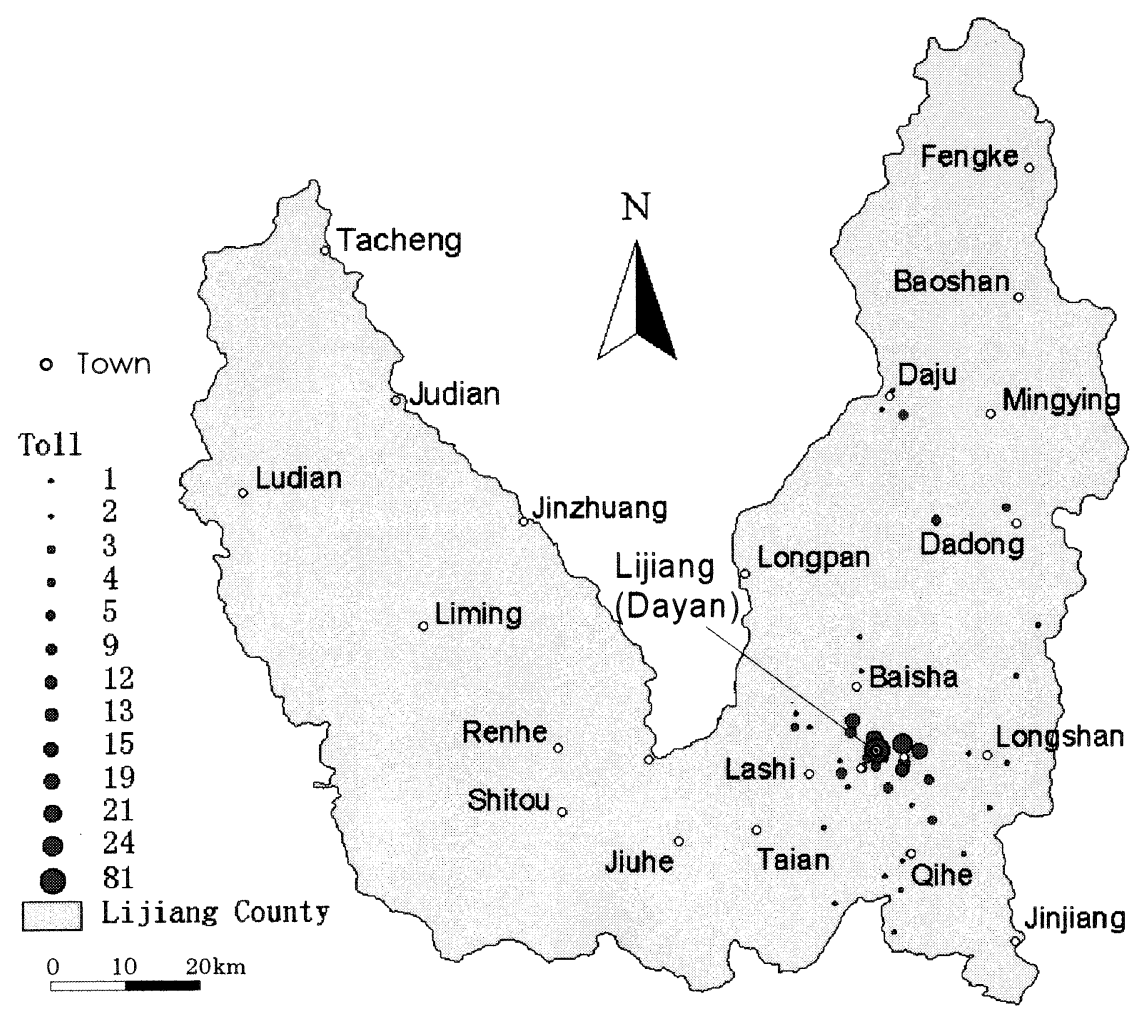

Figure 5. Distribution of persons killed in Lijiang County.

trative boundaries, locations of towns and villages, transportation networks and drainage networks. The maps used are "Administrative Division of Lijiang County" (Comprehensive Scientific Investigation Team of Qinghai-Xizang Plateau and Institute of Geography, Chinese Academy of Science 1990), "Administrative Division of Lijiang Administrative District" (Toponym Office of Lijiang Administrative Region 1999) and "Yunnan Province" (Yunnan Institute of Geography 1997). The mapping and analyses of the data were performed with ArcView, a GIS software package from ESRI, USA.

\section{Distribution of seismic intensity}

As noted above, Han and Zhou (1997) manually produced the contours of seismic intensity based on field observations in 36 towns (Figure 2). We constructed another map of seismic intensity based on the data in Table 5 (Figure 3). The intensity was derived from the detailed house damage ratios, and the number of the data in Table 5 is larger than that in Han and
Zhou (1997), indicating that Figure 3 is more reliable than Figure 2. Figure 3 shows that the distribution of seismic intensity is complex. For example, Intensity $\mathrm{X}$ occurs in three separated areas: around Lijiang ( 1 in Figure 3), near Dadong (2) and near Daju (3). The areas 1 and 3 correspond to basins with thick alluvium as well as the inferred epicenter along the earthquake fault (Figure 1). The thickness of the alluvium in Lijiang Basin attains 1,200 m (PLA 00939 Troops 1979). Intensity IX around Qihe (4 in Figure 3 ) also occurs in and around the basin with thick alluvium (Figure 1).

In contrast, Intensity X near Dadong (2) occurs in an area without thick alluvium. This area is characterized by the tectonic intersection of the Lijiang-Jianchuan fault system (F2 in Figure 1) and the Daju-Dadong fault system (F3). F2 underwent left-lateral strike slip with a rate of $1-2 \mathrm{~mm} / \mathrm{yr}$ and vertical displacement with a rate of $0.2-0.5 \mathrm{~mm} / \mathrm{yr}$ (Wang 1990). F3, characterized by right-lateral strike slip, caused three large earthquakes in the twentieth century with magnitudes between 6 and 6.4 (Liu 


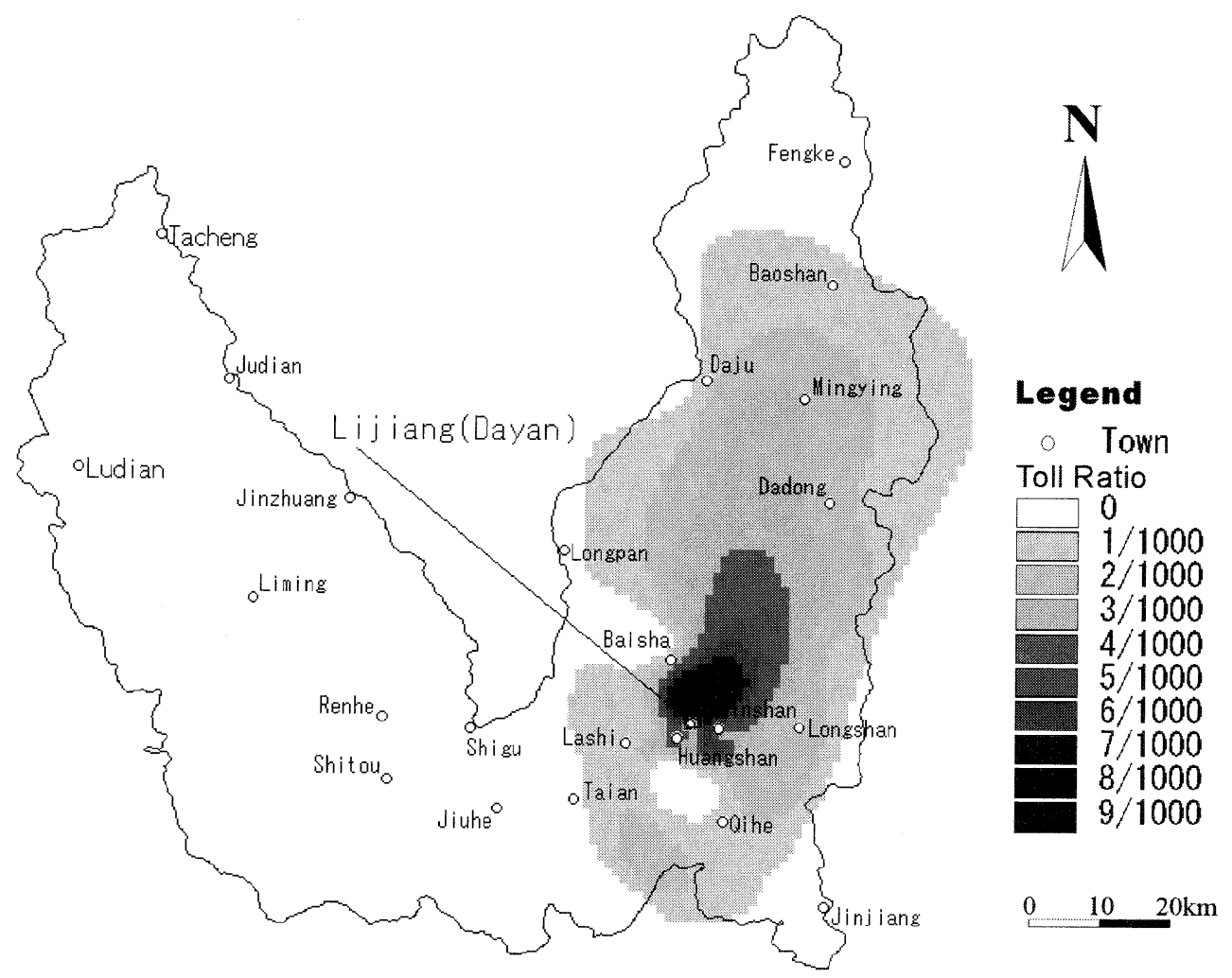

Figure 6. Distribution of death toll ratio.

1998b). Such a complex tectonic structure at the junction of the major active fault systems may have accounted for the enhanced ground movement. The extended distribution of Intensity $\mathrm{X}$ to the NNE of Lijiang (1) appears along the eastern side of the east-dipping earthquake fault. This observation indicates that more serious damage took place on the hanging wall of the fault, as has been often observed elsewhere. The comparison between Figures 1 and 3 shows that Intensity IX and $\mathrm{X}$ mostly occur within the triangular tectonic block bordered by the three major fault systems: LongpanQiaohou (F1), Lijiang-Jianchuan (F2) and DajuDadong (F3). F1 is characterized by left-lateral strike slip with a rate of $2.2 \mathrm{~mm} / \mathrm{yr}$ in the Quaternary (Ran 1990). In addition, the prolongation of the earthquake fault (F4), which also underwent Quaternary left-lateral strike slip, is confined within the tectonic block. Consequently, the structure of fault systems seems to have played an important role in determining the spatial distribution of the earthquake fault, seismic intensity and building damage.

\section{Distribution of building damage ratios}

The damage index $(D I)$ and seismic intensity estimated from $D I$ can be regarded as generalized parameters of earthquake disasters. Mapping of the original building damage ratios permits more precise investigation of disasters. Figure 4 is GIS-produced maps showing the areal ratio of houses belonging to each damage grade. Collapsed houses tend to occur abundantly around Lijiang, Baisha, and Dadong (1 and 2 in Figure 3). Very dense distribution occurs along a NNE-SSW line through Lijiang. The line corresponds to the Lijiang-Jianchuan fault system (F2 in Figure 1) suggesting that the ground motion was accelerated along the fault. Terribly damaged houses occur distinctly near Daju and Qihe (3 and 4 in Figure 3) as well as the area to the NNE of Lijiang. These observations and the distribution of seismic intensity (Figure 3) show that the same intensity grade may result from different types of house 

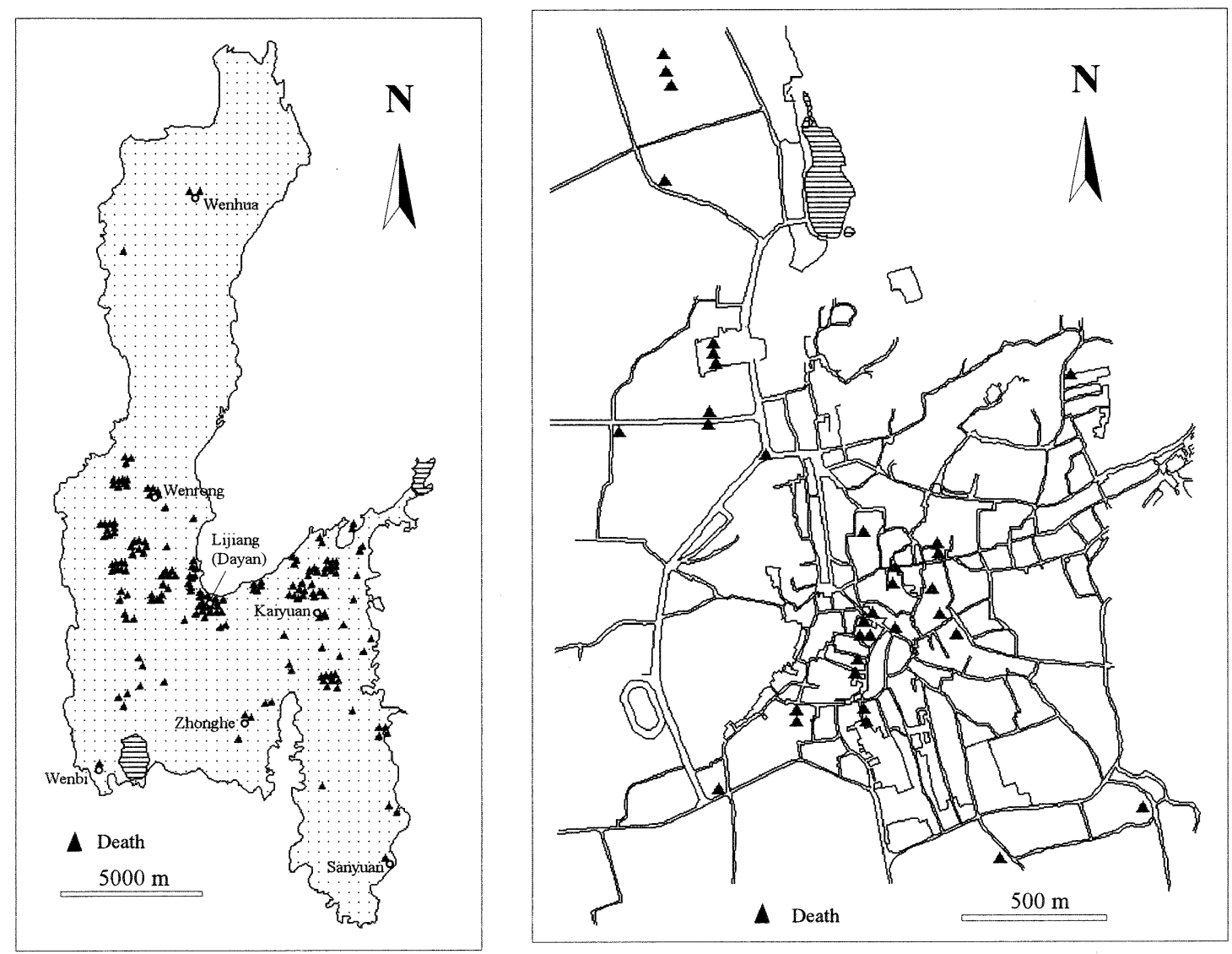

Figure 7. Death distributions in Lijiang Basin (left) and Lijiang town (right).

damage, depending on physical settings such as fault distribution. The ratio of moderately damaged houses is high in the area between Lijiang and Heqing. Despite the proximity to the area of higher intensity, the area experienced relatively weak damage because of the inter-basin condition without thick alluvium.

\section{Distribution of persons killed}

Most deaths due to the earthquake occurred around Lijiang (Figure 5) where many buildings collapsed (Figure 4). In contrast, areas with fewer collapsed houses and abundant terribly damaged houses show a much smaller death toll, reflecting the fact that most victims were crushed below the collapsed buildings.

Figure 6 is a contour map showing the ratio of deaths to total population. The area around Lijiang has high death ratios as well as large death numbers. Although the area close to
Dadong ( 2 in Figure 3 ) also has the high ratio of collapse (Figure 5), the death ratio and toll are much smaller than those around Lijiang. This difference may reflect the density of houses. The death distribution in Lijiang is concentrated in the town center (Figure 7) where many wooden houses stand closely along narrow streets. Under such a situation, quick escape to safe places may have been more difficult than in rural areas.

\section{Conclusions}

This paper has applied GIS to the evaluation of the damage caused by the Lijiang earthquake in China. The mapping and interpolation functions of GIS have facilitated the analyses of earthquake damage and seismic intensity in more detail than the previous studies. Seismic intensity and the damage ratio of houses do not 
decrease simply with an increasing distance from the epicenter, but show complex distribution patterns. Thick alluvium in basins and the structure of fault systems mainly account for this complexity. The density of houses may also have affected the distribution of people killed by the earthquake.

Automated mapping and quantitative data analyses using GIS have been successfully applied to the investigation and mitigation of natural disasters in various countries. In recent years, earthquake disasters repeatedly occurred in China especially in Yunnan Province. It is hoped that modern GIS facilities and spatial databases devoted to Chinese earthquake disasters will be provided in the near future.

\section{Acknowledgment}

Honglin $\mathrm{He}$ acknowledges the financial support from the Postdoctoral Fellowship Program of the Japan Society for the Promotion of Science (No. P00094). Thanks are due to G. Huangfu, X. An, and other people in the China Seismological Bureau for their kind help during our investigation in China. We also thank A. He, Department of Agriculture, University of Tokyo for supplying maps of Lijiang County.

(Received 5 June 2001)

(Accepted 31 October 2001)

\section{References}

China Seismological Breau. 1977. Zonation map of seismic intensity in China, 1:3,000,000. (C)

China Seismological Bureau. 1998. Technique guide book and outline of field work in an earthquake disaster. Beijin: Seismological Press. (C)

Comprehensive Scientific Investigation Team of Qinghai-Xizang Plateau and Institute of Geography, Chinese Academy of Science. 1990. The serial agriculture maps of Naxi's Autonomic County, Lijiang, Yunnan Province. Beijing: Science Press. (C)

Han, X., and Zhou, R. 1997. Intensity distribution of the M 7.0 Lijiang earthquake. Journal of Seismological Research 20-1: 33-46. (C)

Hatayama, M., Matsuno, F., Kakumoto, S., and Kameda, H. 1999. Development of spatial temporal information system DiMSIS. Theory and Application of GIS 7-2: 25-33. (J)
Huangfu, G. 1997. The M 7.0 Lijiang earthquake in Yunnan on February 3, 1996. Journal of Seismological Research 20-1: 1-8. (C)

Investigation Team of Earthquake Influence Field of Tonghai Earthquake. 1977. Intensity distribution and site effect of Tonghai Earthquake. Bulletin of Seismic Engineering Research 3: 1-14. (C)

Iwai, S., Kameda, H., Usui, T., and Morikawa, H. 1996. GIS application to data management for analysis of urban facility damage in Nishinomiya City by the 1995 Hyokoken-Nambu earthquake. Theory and Application of GIS 4-2: 63-73. (J)

Liu Z. 1998a. Earthquale losses. In Lijiang Earthquake of 1996, ed. Yunnan Seismological Bureau and Western Yunnan Earthquake Prediction Study Area, 47-53. Beijing: Seismological Press. (C)

Liu Z. 1998b. Seismotectonics in the shaken area. In Lijiang Earthquake of 1996, ed. Yunnan Seismological Bureau and Western Yunnan Earthquake Prediction Study Area, 64-67. Beijing: Seismological Press. (C)

PLA 00939 Troops. 1979. Reconnaissance Survey Report of Hydrogeology, Lijiang, with 1:200,000 Maps. Beijing, Geological Publishing House. (C)

Ran R. 1990. Lonpan-Qiaohou fault zone. In Active faults in Northwest Yunnan Province, ed. Institute of Geology, China Seismological Burean and Yunnan Seismological Bureau, 83-91. Beijing: Seismological Press. (C)

Toponym Office of Lijiang Administrative Region. 1999. Map of Administrative Division of Lijiang Administrative District. Chengdu: Chengdu Cartographic Publishing House. (C)

Usui, T., and Konagaya, K. 1995. The distribution pattern of debris in the Hansin-Awaji earthquake: A GIS analysis. Geographical Review of Japan 68A-9: 621-633. (J)

Wang J. 1990. Lijiang-Jianchuan fault zone. In Active faults in Northwest Yunnan Province, ed. Institute of Geology, China Seismological Bureau and Yunnan Seismological Bureau, 91-106. Beijing: Seismological Press. (C)

Xie, Y. 1957. A new scale of seismic intensity adapted to the conditions in Chinese territories. Acta Geophysica Sinica 6-1: 35-47. (C)

Yunnan Institute of Geography 1997. Map of Yunnan Province. Chengdu: Chengdu Cartographic Publishing House. (C)

Zhou, Q. 2001. Application of artificial intelligence to delineation of potential sources. $\mathrm{PhD}$ dissertation, Institute of Geology, China Seismological Bureau. (C)

(C): written in Chinese

(J): written in Japanese 